Research Article

\title{
Impact of oral iron therapy on quality of life in patients with heart failure
}

\author{
Manjunath SM ${ }^{\mathrm{a}}$, Janardhan Singh ${ }^{\mathrm{a}, *}$, Kuldeep S. Laller
}

${ }^{a}$ Department of Pharmacology, PGIMS, Rohtak-124001, Haryana, India, ${ }^{\mathrm{b}}$ Department of Cardiology, PGIMS, Rohtak-124001, Haryana, India

Received: 11 December 2012 Accepted: 21 December 2012

\author{
*Correspondence to: \\ Dr. Janardhan Singh, \\ Email: \\ dr_jansingh@yahoo.co.in
}

\begin{abstract}
Background: To assess the effect of oral iron supplementation on quality of life (QOL) in anemic patients with heart failure (HF) and to compare QOL with HF patients without iron treatment.

Methods: Sixty anemic patients (Hb 8-11g/dl) with HF (NYHA-class II and III) with LVEF $<40 \%$ were divided in to 2 groups of 30 each. Group I- received ferrous sulfate $100 \mathrm{mg}$ bid x 90 days + standard treatment for HF. Group IIanemic patients received standard treatment for HF only. Primary end pointQOL was measured by MLWHF questionnaire. Secondary end points are Borg scale for dyspnoea and fatigue and exercise tolerance/ capacity in the form of 6 min. walk distance, haematological parameters, efficacy and safety assessment. Results: There was significant improvement in QOL in iron treated patients as compared to group II (control). Exercise tolerance /capacity, Borg scale for fatigue and dyspnoea showed improvement in patients received iron for 90 days. Haematological parameters were improved gradually with less incidence of fatigue and pallor. Orally administered ferrous sulfate was well tolerated with mild side effects.

Conclusions: Oral iron supplementation in anemic patients with heart failure improves quality of life/ physical functioning in these patients. .
\end{abstract}

Keywords: Quality of life, Ferrous sulfate, Heart failure, Anemia

\section{INTRODUCTION}

Prevalence of heart failure (HF) is increasing in our society and is a common cause of poor quality of life (QOL) and premature death. Approximately 5 million people in the United States have been diagnosed with HF and about 550,000 new cases are diagnosed annually. ${ }^{1}$ Heart failure carries a $50 \%$ mortality at 5 years after symptom onset. ${ }^{2}$ One third of the patients with most severe disease die within the first year after diagnosis. ${ }^{3}$ Heart failure has a major impact on the quality of life. Patients with HF have a significantly lower QOL than age and gender matched person of the community. ${ }^{4}$

For management of congestive HF immediate therapeutic goals are to relieve symptoms and to improve the prognosis. Another aim of health care is to maximize the function in everyday life and to achieve the highest level of QOL within the specific limits imposed by the disease. Quality of life is a relatively new scientific measure to evaluate effectiveness of treatment strategies and the course of a disease. ${ }^{5}$ In CHF- Minnesota Living with Heart Failure Questionnaire (MLHEQ) has proved useful in clinical studies for assessing QOL. Disadvantage of this specific test is that it is difficult to compare across diseases and with controls in the general population. Because it is designed to measure specific aspects of a certain disease, unforeseen side effects of treatment might go undetected. Recently conflicting reports are available demonstrating the role of intravenous, subcutaneous erythropoiesis stimulating agents on QOL in anemic patients with heart failure. ${ }^{6}$ Our main aim in the present study was therefore to assess the effect of oral iron supplementation on quality of life in anemic patients with heart failure.

\section{METHODS}

This was a prospective controlled, open-labeled and comparative clinical study conducted at PGIMS, Rohtak (Haryana) India. An informed written consent was taken from all patients. Total 60 patients of either sex diagnosed with anemia in HF were enrolled for the study. Patients who were eligible as per inclusion and exclusion criteria were allocated to receive one of the two different treatments in an open fashion and subjected to clinical assessment including efficacy and safety. Inclusion criteria-Patients of either sex aged $>18$ years, heart failure 
NYHA class II \& III, exercise tolerance in the form of walk, 6- min walk distance of $<375$ meters, LVEF $<40 \%$, and $\mathrm{Hb}$ level $8-11 \mathrm{~g} / \mathrm{dl}$. Exclusion criteria-Patients with severe infection within previous 1 month, uncorrected primary valvular disease, active myocarditis or constrictive pericarditis, patients with history of cardiac arrest or sustained ventricular tachycardia or fibrillation, within the previous year, patients with unstable angina or acute myocardial infarction, cardiac revascularization procedure or stroke, patients with severe pulmonary, renal or hepatic disease, history of allergy to iron and systolic $\mathrm{BP}<85 \mathrm{mmHg}$ or $>160 \mathrm{mmHg}$, diastolic $\mathrm{BP}>89$ $\mathrm{mmHg}$.

\section{Study Design}

After screening, patients were divided in to 2 groups of 30 each. Group I- Patients with anemia ( $\mathrm{Hb} \mathrm{8-11g/dl)}$ with HF (NYHA class II \& III) given were oral iron, ferrous sulfate $100 \mathrm{mg}$, twice daily for 3 months along with standard treatment of HF. Group II- Patients of anemia with HF were given standard treatment of HF like ACE inhibitors (ramipril 5mg/day), diuretics (furosemide $60 \mathrm{mg} /$ day), inotropic agents (digoxin $0.25 \mathrm{mg} /$ day for 5 days in a week), vasodilators (nitrates- glyceryltrinitrate $2.6 \mathrm{mg}$, twice daily) and hypolipidemic drugs (atorvastatin 20mg/ day) etc was not interrupted in both the groups.

\section{End points}

Primary end point: Quality of life was measured by means of Minnesota Living with Heart Failure Questionnaire (MLHFQ). ${ }^{7}$ The MLHEQ is a 21 item questionnaire assessing how HF has affected the life of the respondent during the last month. The MLHFQ has a scoring range of 0 for no impairment as a result of HF to 105 for maximum impairment. The questions cover symptoms and signs relevant to $\mathrm{HF}$, physical activity, social interaction, sexual activity, work and emotions. Three scores can be determined, an overall score (21 items, 0-105), the physical dimension (8 items, 0-40) and the emotional dimension (5 items, 0-25). Higher MLHFQ score means a worse quality of life.

Secondary end points of study were Borg scale for dyspnoea and fatigue ${ }^{8}$ and exercise tolerance/ capacity, 6minute walk distance. ${ }^{9}$ This test measure the distance (in meters) that a patient can quickly walk on a flat hard surface in a period of $6 \mathrm{~min}$. Efficacy assessment for anemia (signs and symptoms) and haematological parameters like mean corpuscular volume (MCV), mean corpuscular haemoglobin $(\mathrm{MCH}), \mathrm{MCHC}$, packed cell volume (PCV), reticulocyte count (RC) and RBC count. Cell counter method ${ }^{10}$ was used to assess $\mathrm{Hb}, \mathrm{MCV}$, $\mathrm{MCH}, \mathrm{MCHC}, \mathrm{PCV}$, and RBC count.

\section{Safety assessment}

Patients were assessed for side effects of oral iron therapy before treatment and after 15, 45 and 90 days of iron treatment. Any other adverse effects reported by the patients were recorded.

\section{Statistical analysis}

In the descriptive analysis, mean and standard error of mean (SEM) of demographic and various clinical parameters were calculated. Among analytic statistical technique repeated measures ANOVA test was applied for intra group analysis and independent ' $t$ ' test was applied for intergroup analysis. Outcomes were considered statistically significant when $p<0.05$. Analysis was performed using SPSS windows version.

\section{RESULTS}

Total 95 HF patients with anemia were screened. Out of these 26 patients were excluded as they did not match predefined inclusion criteria. Only 60 patients completed the study and rest was lost to follow up.

Quality of life: Quality of life in anemic patients with HF was severely affected. There was significant decrease in MLWHEQ scores after 90 days of oral iron treatment in group I and II as compared to pretreatment values. There was improvement in quality of life in both the groups but improvement was more in iron treated patients. Results are shown in table 1.

Table 1: Effect of oral iron administration on quality of life (MLHFQ Score) in HF patients with anemia.

\begin{tabular}{|c|c|c|c|c|}
\hline \multirow[t]{2}{*}{ Groups } & \multirow[t]{2}{*}{$\begin{array}{l}\text { Pretre } \\
\text { atment }\end{array}$} & \multicolumn{3}{|c|}{ After treatment } \\
\hline & & 15 days & 45 days & 90 days \\
\hline I & $\begin{array}{l}330.87 \\
\pm 5.01\end{array}$ & $\begin{array}{l}331.40 \pm \\
4.81\end{array}$ & $\begin{array}{l}336.50 \pm 5 \\
.08\end{array}$ & $\begin{array}{l}347.03 \pm 4 \\
93 *\end{array}$ \\
\hline II & $\begin{array}{l}325.70 \\
\pm 5.05\end{array}$ & $\begin{array}{l}326.30 \pm \\
4.57\end{array}$ & $\begin{array}{l}328.43 \pm 5 \\
.73\end{array}$ & $\begin{array}{l}332.07 \pm 5 . \\
23 @\end{array}$ \\
\hline $\begin{array}{l}* p<0.0 \\
\text { @ } p<0 .\end{array}$ & $\begin{array}{l}\text { en com } \\
\text { hen col }\end{array}$ & $\begin{array}{l}\text { red with } \\
\text { ared witl }\end{array}$ & $\begin{array}{l}\text { etreatment } \\
\text { roup I. }\end{array}$ & \\
\hline
\end{tabular}

Decreased Borg scores for dyspnoea and fatigue were noted in iron treated group. There were marked improvement in both dyspnoea and fatigue in patients received iron treatment for 90 days as compared to group I (table 2). There was significant increase in exercise tolerance as noted in the form of $6 \mathrm{~min}$. walk distance, after 45 and 90 days of iron treatment. Haematological parameters like $\mathrm{Hb}$, peripheral blood film (PBFmicrocytic-hypochromic anemia), reticulocyte count (RC), mean corpuscular volume (MCV), mean corpuscular haemoglobin $(\mathrm{MCH}), \mathrm{MCHC}$, packed cell volume (PCV), and RBC count were significantly increased after 3 months treatment with iron while incidence of microcytic-hypochromic anemia was reduced (table 3 ). Incidence of fatigue and pallor were gradually reduced after oral iron supplementation in anemic patients with HF. Orally administered ferrous sulfate was well tolerated with few mild side effects (nausea, diarrhea). 
Table 2: Effect of oral iron supplementation on Borg dyspnoea and fatigue score in anemic patients with heart failure. Data presented as Mean \pm SEM.

\begin{tabular}{|c|c|c|c|c|}
\hline \multirow[t]{2}{*}{ Groups } & \multirow[t]{2}{*}{$\begin{array}{l}\text { Pretre } \\
\text { atment }\end{array}$} & \multicolumn{3}{|c|}{ After iron treatment } \\
\hline & & 15 Days & 45 Days & 90 Days \\
\hline & & \multicolumn{3}{|c|}{ Borg Dyspnoea Score } \\
\hline \multirow{2}{*}{ I } & $7.23 \pm$ & $7.06 \pm$ & $6.16 \pm$ & $4.73 \pm$ \\
\hline & 0.22 & 0.22 & $0.20^{*}$ & $0.21^{*}$ \\
\hline \multirow{3}{*}{ II } & $7.03 \pm$ & $7.00 \pm$ & $6.46 \pm$ & $5.86 \pm$ \\
\hline & 0.27 & 0.26 & 0.25 & $0.28^{* @}$ \\
\hline & \multicolumn{4}{|c|}{ Borg Fatigue Score } \\
\hline \multirow{2}{*}{ I } & $6.83 \pm$ & $6.53 \pm$ & $5.96 \pm$ & $5.03 \pm$ \\
\hline & 0.25 & 0.22 & 0.22 & $0.17^{*}$ \\
\hline \multirow{2}{*}{ II } & $7.00 \pm$ & 6.73 & $6.13 \pm$ & $5.86 \pm$ \\
\hline & 0.29 & \pm 0.27 & 0.26 & $0.29^{* \#}$ \\
\hline
\end{tabular}

\section{DISCUSSION}

Present study revealed that oral iron administration in anemic patients with HF improved quality of life (QOL), dyspnoea, fatigue, exercise tolerance and haematological parameters. The improvement in QOL after iron may be due to improved cardiac function via improving delivery of oxygen to heart muscle or aerobic metabolism. In anemic patients oxygen carrying capacity of $\mathrm{Hb}$ is markedly reduced. Thus improvement in $\mathrm{Hb}$ levels lead to better oxygen supply to heart and other tissues. It is well known that QOL is affected by gender and age of patients. Patients with $\mathrm{HF}$ are more often female and older $^{11,12}$ and in general it would seem that QOL is lower in patients with HF. The possible differences in QOL in group I and group II of present study were not due to differences in age and gender since the base line characteristics of population of this study are almost similar ( mean age in group I and II were, 55.63 \pm 1.73 and $57.73 \pm 2.38$ respectively, $\mathrm{M} / \mathrm{F}$ ratio (23/7 [I] and 22/8 [II]). The question related to the physical dimension that assessed fatigue and dyspnoea showed higher mean score than the others indicating that decrease in QOL in anemic HF patients is more concerned to the impact of these symptoms in every day life. In fact these symptoms (fatigue, dyspnoea) characterize the progressive worsening of $\mathrm{HF}$, leading to limitations of lives of patients. Further, HF is also associated to the limitations in activities of daily living, inability to work and loss of independence. ${ }^{13}$ Loss of functions is associated with physical symptoms, adverse effects of drugs, to comorbidities and loss of cognitive functions. There is strong association between physical symptoms and iron deficiency. Results of our study showed that physical symptoms (fatigue, dyspnoea) were improved markedly in anemic patients after iron administration along with improved QOL in these patients. Patients with HF change their life style because they can not do some tasks due to dyspnoea, fatigue and edema. ${ }^{14}$

In conclusion, oral iron supplementation improves QOL in anemic patients with HF and improvement in QOL may be due to improvement in physical symptoms and exercise tolerance after iron therapy.

Table 3: Effect of oral iron treatment on haematological parameters in anemic patients with heart failure.

\begin{tabular}{|c|c|c|c|c|c|}
\hline Groups & Parameters & Before treatment & \multicolumn{3}{|c|}{ After Treatment } \\
\hline & & & 15 Days & 45 Days & 90 Days \\
\hline I & $\mathrm{Hb}(\mathrm{g} / \mathrm{dl})$ & $10.03 \pm 0.12$ & $10.07 \pm 0.12$ & $10.50 \pm 0.14$ & $11.17 \pm 0.18^{*}$ \\
\hline II & -do- & $9.94 \pm 0.14$ & $9.92 \pm 0.14$ & $9.83 \pm 0.14$ & $9.72 \pm 0.14^{* *}$ \\
\hline I & PBF & 16 & 16 & 15 & 11 \\
\hline II & - do- & 17 & 17 & 17 & $19 @$ \\
\hline I & $\mathrm{RC}(\%)$ & $0.58 \pm 0.01$ & $0.62 \pm 0.01^{*}$ & $0.71 \pm 0.01^{*}$ & $0.81 \pm 0.01^{*}$ \\
\hline II & -do- & $0.57 \pm 0.01$ & $0.56 \pm 0.01^{* *}$ & $0.56 \pm 0.01^{* *}$ & $0.55 \pm 0.01^{* *} \#$ \\
\hline I & MCV (fl) & $86.14 \pm 1.11$ & $86.27 \pm 1.11$ & $87.07 \pm 1.11^{*}$ & $88.30 \pm 1.11^{*}$ \\
\hline II & -do- & $85.63 \pm 1.23$ & $85.59 \pm 1.23^{* *}$ & $85.44 \pm 1.23^{* *}$ & $84.86 \pm 1.23^{* *} \#$ \\
\hline I & MCH (pg) & $24.37 \pm 1.54$ & $24.47 \pm 0.29$ & $24.80 \pm 0.28$ & $25.38 \pm 0.29^{*}$ \\
\hline II & -do-- & $24.43 \pm 1.60$ & $24.40 \pm 0.29^{* *}$ & $24.27 \pm 0.29^{* * *}$ & $24.10 \pm 0.30^{* *} \#$ \\
\hline I & MCHC (g/dl) & $28.40 \pm 0.42$ & $28.51 \pm 0.42$ & $28.91 \pm 0.42$ & $29.50 \pm 0.42^{*}$ \\
\hline II & -do- & $28.60 \pm 0.35$ & $28.56 \pm 0.35^{* *}$ & $28.41 \pm 0.35^{* *}$ & $28.21 \pm 0.35^{* * *} \#$ \\
\hline I & PCV (\%) & $35.60 \pm 0.47$ & $35.63 \pm 0.46$ & $36.33 \pm 0.47^{*}$ & $37.23 \pm 0.48^{*}$ \\
\hline II & -do-- & $34.93 \pm 0.51$ & $34.90 \pm 0.51^{* * *}$ & $34.86 \pm 0.52^{* *}$ & $34.57 \pm 0.54^{* *} \#$ \\
\hline I & RBC count & $4.14 \pm 0.05$ & $4.19 \pm 0.05$ & $4.33 \pm 0.05^{*}$ & $4.49 \pm 0.05^{*}$ \\
\hline II & --do- & $4.09 \pm 0.06$ & $4.06 \pm 0.06^{* *}$ & $4.00 \pm 0.06^{* *}$ & $3.93 \pm 0.06^{* * *} \#$ \\
\hline
\end{tabular}


Funding: No funding sources

Conflict of interest: None declared

Ethical approval: The study was approved by the

Institutional Ethics Committee

\section{REFERENCES}

1. Croft JB, Giles WH, Pollard RA,Keenan NL, Casper ML, Anda RF. Heart failure survival among older adults in the United States: A poor prognosis for an emerging epidemic in the Medcare population. Arch Intern Med 1999;159:505-10.

2. Zannad F, Briancon S, Juilliere Y. Incidence and etiologic features and outcomes of advanced chronic heart failure. The EPICAI study. J Am Coll Cardiol 1999;33:734-41.

3. Goldberg RJ, Ciampa J, Lessard D, Meyer TE, Spencer FA. Long term survival after heart failure: A contemporary population based perspective. Arch Intern Med 2007;167:490-6.

4. Lesman-Leegte I, Jaarsma T, Coyne JC, Hillege HL, Van-Veldhulsen DJ, Sanderman R. Quality of life and depressive symptoms in the elderly: a comparison between patients with heart failure and age and gender matched community controls. J Card Fail 2009;15:17-23.

5. Bullinger M. Health related quality of life and subjective health. Overview of the status of research for new evaluation criteria in medicine. Psychother Psychosom Med Psychol 1997;47:76-91.

6. Ghali JK, Anand IS, Abraham WT, Fonarow GC, Greenberg B. Krum H. Randomized double blind trial of darbopoietin alfa in patients with symptomatic heart failure and anemia. Circulation 2008;117:52635 .

7. Rector TS, Kubo SH, Cohn JN. Patients self assessment of their congestive heart failure, part 2 : content, reliability and validity of a new measure, the Minnesota Living with Heart Failure Questionnaire. Heart Fail 1987;3:198-209.

8. Borg GA. Psychophysical bases of perceived exertion. Med Sci Sports Exerc 1982;14:377-81.

9. ATS Committee on proficiency standards for clinical pulmonary function laboratories. ATS statement: guidelines for the six minutes walk test. Am J Resp Crit Care Med 2002;166:111-7.

10. Coulter WH. High speed automatic blood cell counter and cell size analyser. Proceeding of national electronic conference 1956;12:1034-40.

11. Paulus WJ, Van-Ballegoij JJ. Treatment of heart failure with normal ejection fraction: an inconvenient truth. J Am Coll Cardiol 2010;55:526-37.

12. Kindermann M, Reil JC, Pieske B, Van-Veldhuisen DJ, Bohm M. Heart failure with normal left ventricular ejection fraction: What is the evidence? Trends Cardiovasc Med 2008;18:280-92.

13. Evangelista LS, Kagawa-Singer M, Dracup K. Gender differences in health perceptions and meaning in person living with heart failure. Heart Lung 2001;30:167-76.

14. Hurst JW. Exame inicial para diagnostic cardiovascular. Rio de Janeiro: Revinter: 2000; p 2930.

doi: 10.5455/2319-2003.ijbcp20130108

Cite this article as: Manjunath SM, Singh J, Laller KS. Impact of oral iron therapy on quality of life in patients with heart failure. Int J Basic Clin Pharmacol 2013;2:43-6. 